\title{
As bases conceituais da educação profissional e tecnológica nas histórias de vida de professoras do IFPA campi de Bragança e Tucuruí
}

\section{The conceptual bases of professional and technological education in the life stories of teachers of IFPA campi of Bragança and Tucuruí}

Recebido: 21/04/0020 | Revisado: 25/06/2020 | Aceito: 12/03/2021 | Publicado: 16/06/2021

Robson de Sousa Feitosa ORCID: https://orcid.org/0000-0003-13918585

Instituto Federal de Educação, Ciência e Tecnologia do Pará

E-mail: rsfeitosa77@hotmail.com

Como citar: FEITOSA, R. S.; As bases conceituais da educação profissional e tecnológica nas histórias de vida de professoras do IFPA campi de Bragança e Tucuruí. Revista Brasileira da Educação Profissional e Tecnológica, [S.I.], v. 1, n. 20, p. e9951, jun. 2021. ISSN 2447-1801.

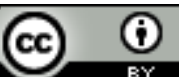

This work is licensed under a Creative Commons Attribution 4.0 Unported License.

\begin{abstract}
Resumo
O trabalho tem por objetivo investigar as bases da Educação Profissional e Tecnológica (EPT) nas narrativas de vida de quatro professoras do IFPA, nos campi de Bragança e Tucuruí. $O$ foco da pesquisa são os processos de identificação das pesquisadas sobre si mesmas como professoras e o papel das experiências de vida que repercutem na formação profissional docente. Utiliza-se como instrumental metodológico a história de vida com o uso da história oral e entrevista. O estudo trata das bases conceituais que fundamentam a EPT, que são: trabalho como princípio educativo, formação humana integral e politecnia, e descreve as histórias de vida das quatro professoras dos dois campi. Os resultados mostram que as bases estão presentes nas falas, sem o conhecimento conceitual; que se identificam com a prática docente; e que as experiências da vida particular encontram vazão na formação profissional.
\end{abstract}

Palavras-chave: Bases Conceituais da EPT. Histórias de Vida. Experiência Profissional.

\begin{abstract}
This work aims to investigate the basis of Professional and Technological Education (PTE) in the life narratives of four teachers from Federal Institute of Para, in the Bragança and Tucuruí Campuses. The focus of the research is on the processes of identifying those researched teachers about themselves as professionals and the role of life experiences that have an impact on teacher professional formation. Life history is used as a methodological tool with the use of oral history and interview. The study deals with the conceptual bases that underlie PTE, which are: work as an educational principle, complete human formation and polytechnic, and describes the life stories of the four teachers on the two campuses. The results show that the bases are present in the speeches, without conceptual knowledge; that identify with teaching practice; and that the experiences of private life find outlet in professional formation.
\end{abstract}

Keywords: Conceptual Basis of PTE, Life Stories, Professional Experience. 


\section{INTRODUÇÃO}

A trajetória de vida de um indivíduo diz muito sobre ele, pois as experiências pessoais, os livros que leu e as pessoas que passaram por sua vida moldam sua personalidade e caráter e, por conseguinte, repercutem na sua compreensão de mundo e na sua prática pedagógica. Os sujeitos que trabalham como docentes na Educação Profissional e Tecnológica (EPT) carregam uma história pessoal que diz muito sobre os professores que se constituíram na prática.

Assim, surge a problemática a ser respondida, a partir das discussões a respeito da EPT no Mestrado em Educação Profissional e Tecnológica no Instituto Federal de Educação, Ciência e Tecnologia do Amazonas (IFAM): como as concepções de EPT são construídas por professoras nos campi de Bragança e Tucuruí do Instituto Federal de Educação, Ciência e Tecnologia do Pará (IFPA)? Quais as imagens que essas professoras têm de si? E como os aspectos de suas histórias de vida repercutem nas suas práticas docentes? Para tanto, será utilizado o método da história de vida, com uso da história oral, o qual implica investigar como as trajetórias de vida das docentes influenciam as concepções de EPT construídas por elas.

Foram selecionadas de forma aleatória duas professoras de cada campus, sendo uma das disciplinas técnicas e outra das disciplinas de conhecimentos gerais. Procuramos também selecionar uma professora com mais tempo de trabalho no campus e outra com pouco tempo na instituição. Utilizamos como instrumento de pesquisa a história de vida, com as técnicas de história oral por meio de entrevista feita com roteiros previamente definidos, tomando como fundamento as ideias de Thompson (2002).

No IFPA campus Bragança, que iniciou suas atividades em 2008 e teve seu prédio inaugurado em 2010, optou-se por entrevistar uma professora com mais tempo de atuação em disciplina básica e uma professora de disciplina técnica com menos de três anos de atividade profissional no instituto.

No campus Tucuruí, criado em 1994 como Unidade Descentralizada de Ensino (UNED), depois transformado em CEFET e posteriormente, em 2008, convertido em campus do IFPA, foi selecionada uma professora da área técnica com mais tempo de atuação e uma professora da educação geral com menos tempo de atividade.

$\mathrm{Na}$ apresentação do texto, inicialmente tratamos das bases conceituais que fundamentam a EPT e sua estrutura para, então, trazer à baila as histórias de vida das quatro professoras dos dois campi, estabelecendo aproximações conceituais das categorias abordadas e os resultados apontados no estudo.

\section{DA ESTRUTURA DA EDUCAÇÃO PROFISSIONAL E TECNOLÓGICA}

Conceituar a EPT não é tarefa fácil em razão das várias políticas públicas de décadas passadas, que deram atribuições e finalidades específicas ao sabor de cada grupo político que governou o país. No entanto, para Cattani e Ribeiro (2012, p. 203): 


\begin{abstract}
A formação profissional (FP) designa os processos educativos que permitam ao indivíduo adquirir e desenvolver conhecimentos teóricos, técnicos e operacionais relacionados à produção de bens e serviços quer esses processos sejam desenvolvidos nas escolas, quer nas empresas e nos variados ambientes de trabalho. A FP, como outras dimensões da vida em sociedade, está condicionada pelas relações sociais e pelos embates entre capital e trabalho na esfera da produção, refletindo, também, relações de poder e concepções de mundo dos agentes.
\end{abstract}

Inicialmente, no Brasil, a educação profissional esteve voltada para as questões assistenciais (CAIRES; OLIVEIRA, 2016), com o objetivo de profissionalizar as pessoas que estavam em situação de marginalização. Posteriormente, com o desenvolvimento industrial do país, o ensino profissional passou a ter como meta a capacitação de mão de obra para o mercado de trabalho.

A lei 9.394, de 20 de dezembro de 1996, que estabelece as diretrizes e bases da educação nacional, em sua redação original, assim definia a educação profissional, no artigo 39: "A educação profissional, integrada às diferentes formas de educação, ao trabalho, à ciência e à tecnologia, conduz ao permanente desenvolvimento de aptidões para a vida produtiva" (BRASIL, 1996, grifo nosso).

Contudo, a lei 11.741, de 16 de julho de 2008, alterou o referido artigo, acrescentando a expressão "tecnológica" ao "profissional": "A educação profissional e tecnológica, no cumprimento dos objetivos da educação nacional, integra-se aos diferentes níveis e modalidades de educação e às dimensões do trabalho, da ciência e da tecnologia" (BRASIL, 2008a, grifo nosso).

A atualização retirou a expressão "conduz ao permanente desenvolvimento de aptidões para a vida produtiva", levando a crer que o foco da educação profissional não é mais simplesmente a atenção às forças produtivas para atender o capital. Assim, podemos perceber que a EPT, nos moldes da atual legislação, é uma modalidade de ensino que está integrada a todos os outros níveis e modalidades.

Neste contexto de atualização legislativa e desenvolvimento de políticas sociais, surgem os Institutos Federais, criados pela lei 11.892, de 29 de dezembro de 2008 (BRASIL, 2008b) com o objetivo, a nível federal, de ofertar a educação profissional.

Os campi investigados nessa pesquisa, de Bragança e Tucuruí, ofertam a EPT em todas as suas modalidades.

\title{
3 DAS BASES DA EDUCAÇÃO PROFISSIONAL E TECNOLÓGICA
}

As bases da EPT tratadas são três: o trabalho como princípio educativo, a formação humana integral ou omnilateral e a politecnia. 


\subsection{O TRABALHO COMO PRINCÍPIO EDUCATIVO}

De acordo com Saviani (2007), nos primórdios da humanidade, o ser humano aprendeu a interagir com a natureza de modo racional e, primando por sua sobrevivência, passou então a subjugá-la às suas necessidades. A partir dessa interação homem/natureza, surge a relação entre trabalho/educação, compreendendo o trabalho em seu sentido ontológico, ou seja, desta interação com a natureza e da forma transformadora que isso resulta.

Assim, quanto mais o ser humano interagia com a natureza mais ocorriam, dialeticamente, as transformações que iriam resultar o ser humano no que ele é hoje, ou seja:

Se a existência humana não é garantida pela natureza, não é uma dádiva natural, mas tem de ser produzida pelos próprios homens, sendo, pois, um produto do trabalho, isso significa que o homem não nasce homem. Ele forma-se homem. Ele não nasce sabendo produzirse como homem. Ele necessita aprender a ser homem, precisa aprender a produzir sua própria existência. Portanto, a produção do homem é, ao mesmo tempo, a formação do homem, isto é, um processo educativo (SAVIANI, 2007, p. 154).

E foi assim, na tentativa e no erro, que o ser humano começou a agregar conhecimentos à sua vida cotidiana. Esses conhecimentos necessitavam ser transmitidos de forma prática na própria interação para as próximas gerações e, a cada interação com a natureza e com os outros, iam se aperfeiçoando as técnicas do trabalho.

Contudo, quando a população cresceu e a sociedade começou a ficar mais complexa, o ser humano abandonou sua vida comunal, começando a se organizar em cidades e deixando o antigo modelo gentílico-tribal. $O$ crescimento populacional gerou uma apropriação da propriedade, ocorrendo assim a divisão do trabalho e as especializações necessárias para uma vida mais complexa, cujo objetivo foi o de organizar as cidades. Para tanto, começaram a surgir as funções políticas, destinadas àqueles que não tinham necessidade de produzir, pois eram os detentores da propriedade privada.

Neste momento de complexidade das organizações sociais, a classe dominante sentiu a necessidade de criar um espaço dedicado à formação dos futuros dirigentes. Eis que emerge a escola:

A palavra escola deriva do grego e significa, etimologicamente, o lugar do ócio, tempo livre. Era, pois, o lugar para onde iam os que dispunham de tempo livre. Desenvolveu-se, a partir daí, uma forma específica de educação, em contraposição àquela inerente ao processo produtivo. Pela sua especificidade, essa nova forma de educação passou a ser identificada com a educação propriamente dita, perpetrando-se a separação entre educação e trabalho (SAVIANI, 2007, p. 154). 
Percebe-se assim que a escola se apresenta como um espaço reservado aos abastados da cidade, fato que perdurou até o advento das grandes revoluções do século XVIII, quando a escola assume o papel de centro oficial da educação, inicialmente como um local de formação geral a todos. No entanto, o tipo de educação "para todos" não se revela na prática, pois a origem de classe acaba por influenciar o tipo de educação que os indivíduos recebem. Tem-se a conhecida dualidade de papéis na formação humana, onde a escola assume um tipo manual/profissional destinada aos filhos dos trabalhadores e outra intelecto/dirigente para os sujeitos advindos da classe burguesa.

Esse modelo de educação persiste até hoje. Porém, outro modelo é necessário: um modelo que privilegie de fato a educação como um instrumento de libertação e não de opressão. Assim, no seio dos conflitos entre capital e trabalho, desenvolve-se uma proposta que retoma o sentido ontológico do trabalho como algo intrínseco ao ser humano, pois é considerado fruto produtivo e transformador de sua relação com a natureza.

Desta forma, tendo o trabalho como princípio educativo, alguns teóricos do socialismo, entre eles Marx e Gramsci, propõem que a educação deva privilegiar as relações produtivas, fora dos moldes capitalistas que conhecemos hoje, fazendo com que os estudantes consigam compreender como ocorre a transformação do conhecimento (ciência potencial) em potencial material. Isso é o que Marx chamava de politecnia (SAVIANI, 2007).

Assim, a proposta de ter o trabalho como princípio educativo pressupõe a necessidade de romper com o atual modelo de educação voltado apenas para o mercado de trabalho. Ainda que o trabalho como princípio educativo esteja inserido nos documentos legais que regulam a educação brasileira, em especial o ensino médio, este só poderá ser efetivado na medida em que a educação nos ajude a compreender que o trabalho cria e recria a existência humana nos aspectos econômico, artístico, cultural e tecnológico. Da mesma forma, quando a educação proporciona entender esse papel do trabalho, compreendendo como atravessa as vidas das pessoas em seus vários aspectos, contribuímos para o reconhecimento das condições de exploração que a atual sociedade nos submete e o que podemos fazer para superá-las.

Neste sentido, uma proposta de educação progressista e comprometida com o desenvolvimento social é a de um ensino voltado para a formação do homem integral, onde o educando possa compreender os fenômenos naturais e sociais. Essa educação deve ser voltada para a compreensão das relações de produção, com bases politécnicas, introduzindo assim o estudante no mundo da práxis.

\subsection{A FORMAÇÃO HUMANA INTEGRAL OU OMNILATERAL}

Uma formação humana integral pressupõe uma educação que leve em conta todos os aspectos da vida, o trabalho, a ciência e a cultura, e que prepare o aluno para além de ser um mero reprodutor.

\section{Essa concepção de educação integral propõe}


[...] superar o ser humano dividido historicamente pela divisão social do trabalho entre a ação de executar e a ação de pensar, dirigir ou planejar [...]. Como formação humana, o que se busca é garantir ao adolescente, ao jovem e ao adulto trabalhador o direito a uma formação completa para a leitura do mundo e para a atuação como cidadão pertencente a um país, integrado dignamente à sua sociedade política (CIAVATTA, 2005, p. 85).

Assim, é necessário instituir um projeto social que vise romper com a mera preparação para o mercado de trabalho. Esse projeto de sociedade deve estar ancorado numa concepção de ensino integrado que articule formação técnica e formação geral, tendo por base o trabalho, a ciência e a cultura como pontos essenciais.

Para a consecução dessa formação humana integral, é preciso considerar homens e mulheres como sujeitos históricos que vivem numa dada realidade utilizando-se do trabalho para satisfazer suas necessidades e, para isso, lançam mão dos conhecimentos, das práticas, dos valores e dos saberes que a humanidade acumulou ao longo da história, através da ciência e da cultura.

Concordamos com Ramos (2009), sobre outro aspecto a ser considerado na busca por pensar a educação humana por meio da integração, que é conceber a realidade como uma totalidade, onde o que se vivencia no cotidiano tem múltiplas relações. Dessa forma, os processos educativos que perpassam um currículo integrado de formação humana precisam considerar a superação da dualidade histórica de formação humana que os sistemas de educação têm assumido.

Para isso, é necessário apreender a realidade de uma maneira totalizante, primando por situações de aprendizagens que compreendam os conceitos, procedimentos e atitudes como integrantes de um conjunto de relações de uma realidade maior que se estuda, através de práticas interdisciplinares, de tal forma que o currículo integrado provoque a integração dos conhecimentos, por meio de um fazer docente diferenciado, ou seja, professores de formação geral e de formação profissional trabalhando temas complexos, mas com flexibilidade e multiplicidade de olhares sobre a realidade.

\subsection{A POLITECNIA}

A politecnia pode ser considerada como um instrumento para se chegar a uma formação humana integral, considerando o homem como um ser histórico-cultural e a educação como uma prática social tendente a desenvolver múltiplas potencialidades: cognitivas, estéticas, físicas e sociais.

Saviani (2003) enfatiza que é possível concebê-la como base para a construção de uma perspectiva de formação humana integral dentro do sistema de ensino do Brasil, indicando que se pode pensar em caminhos que apontem as saídas para a superação das amarras que vivenciamos na realidade. 
Pistrak (2015), interpretando Marx, corrobora esse entendimento ao afirmar que

Marx [...] considerou possível propor a demanda de uma escola politécnica como exigência programática da classe operária nos marcos da sociedade capitalista. É evidente que com a conquista do poder pela classe operária, a escola politécnica tornar-se-á inevitável [...] (p. 30).

É importante destacar que a politecnia tem desvios quando a consideram um amontoado de técnicas, de caráter artesanal. Neste sentido, Pistrak (2015, p. 183) enfatiza que "muitas vezes, sob politecnização se entende apenas que as crianças são dotadas de uma quantidade conhecida de habilidades de caráter artesanal". Por outro lado, o mesmo autor posiciona-se mais à frente de maneira oposta, indicando que "devemos lutar contra isso. Não podemos permitir que se reduza a organização de oficinas de carpintaria e serralheria".

Para além dessa limitação, é preciso observar que ao invés de pensar a integração dos conhecimentos dentro do currículo, com cada profissional respondendo por sua área de conhecimento numa atividade tida integrada ou interdisciplinar, deve-se buscar que cada um dê também sua contribuição sobre as outras áreas de conhecimento, procurando o diálogo propositivo para a concretização de uma escola politécnica. Como enfatiza Freitas e Caldart (2017):

A escola politécnica diferencia-se de uma escola profissional por ter o centro de gravidade na compreensão dos processos de trabalho, no desenvolvimento da capacidade de unir num todo único teoria e prática, na capacidade de compreender a interdependência dos fenômenos conhecidos, enquanto que o centro de gravidade da escola profissional passa pela capacitação dos estudantes em habilidades de trabalho (FREITAS; CALDART, 2017, p. 153).

Assim, a politecnia traz a ideia de compreensão do fenômeno de que o homem se constrói pelo trabalho, e não o contrário, quando ele é deformado, expropriado e manipulado pelo capital. Essa educação politécnica tem como objetivo a transformação dessa realidade de exploração, considerando a emancipação do homem em face da exploração do capital.

\section{NOTAS SOBRE HISTÓRIAS DE VIDA DE PROFESSORAS DOS CAMPIDO IFPA}

Ao optar pela história de vida de professores, a intenção é documentar a trajetória daqueles que contribuem para a educação do País, em especial aos que estão nos seus respectivos campi do IFPA, e apontar categorias que identificam como se dá a formação docente na EPT. Também interessa perceber, nas falas e reminiscências, como eles se veem e como enxergam o processo educativo. 
Partimos de Nóvoa (1995, p. 17) ao afirmar que a "maneira como cada um de nós ensina está diretamente dependente daquilo que somos como pessoa quando exercemos o ensino". Desta forma, passamos a apresentar as entrevistas das professoras, descrevendo trechos que revelam suas compreensões a respeito das bases da EPT, de suas identidades e de suas experiências profissionais.

Utilizaremos as letras do alfabeto para designar as entrevistadas. Assim, a primeira história a ser narrada é a da professora A, que é Engenheira Civil com especialização em Instalações Prediais e mestrado em Tecnologias Ambientais e Recursos Hídricos. Nasceu no interior do Rio Grande do Sul, na cidade de Santo Antônio da Patrulha, e lá permaneceu até os 9 anos. A professora recorda que era uma comunidade rural, bem familiar, na qual convivia entre primos e tios.

A professora ainda diz que seus pais nunca cobraram dedicação aos estudos, mas ela percebeu cedo que aquele era o seu caminho. E sempre estudou para ser uma das melhores alunas. Relata ainda que sempre teve facilidade para a área de exatas e a certeza de que o único caminho para melhorar de vida era a educação.

É interessante observar nesses relatos sobre as dificuldades e superações como a educação pode ser um instrumento de emancipação. Esses traços podem ser observados também na história de vida de outros professores. Aliás, todas as entrevistadas têm origem em famílias pertencentes a seguimentos economicamente desfavorecidos e sempre trabalharam muito para sobreviver.

A professora B é formada em língua portuguesa com habilitação também para o Espanhol. Relata que nunca se imaginou como docente e não tem exemplos em sua família de pessoas que seguiram essa carreira. Destaca que os pais não terminaram o nível médio e que ela e os irmãos foram criados pela avó paterna que também não teve acesso ao ensino médio.

Eu sempre tive um gosto por estudo, lembro bem que a minha grande motivação foi na escola, porque sempre que eu apresentava seminário, era muito elogiada, mas eu não tinha vontade de ser professora. Eu nasci em Capanema e minhas professoras sempre falavam que eu poderia ser professora porque eu explicava muito bem, sempre me motivavam nesse sentido.

Percebe-se a importância do professor como incentivador para o futuro do adolescente, demonstrando que uma boa orientação pode definir os rumos do aluno. Portanto, a escola não é apenas um espaço para ensinar conteúdos, mas para dar o direcionamento necessário ao aluno e para ficar atenta às suas necessidades, como recorda a entrevistada ao ter sido indicada por suas professoras do ensino médio para um estágio no Banco da Amazônia.

No banco, ela trabalhava das $8 \mathrm{~h}$ às $14 \mathrm{~h}$, depois ia para a escola, onde permanecia das $14 \mathrm{~h}$ às $18 \mathrm{~h}$. Quando era a noite, ia para o cursinho pré-vestibular. Relata que não sabia o que queria fazer, e então um professor perguntou se gostava de língua portuguesa e língua estrangeira. Foi ele quem a orientou sobre a legislação que tornava o espanhol disciplina obrigatória, indicando que essa seria uma área promissora. Assim, ela ingressou no curso de Letras, com ênfase em espanhol. 
A professora $C$ é formada em Filosofia e nasceu em Belém. Seu pai trabalhava como caldeireiro na fábrica de sabonetes Phebo na capital. Depois, a família resolveu se mudar para Itaituba. Lá, seu pai foi trabalhar na procura de ouro nos garimpos da região. A professora voltou para Belém para cursar o ensino médio e a graduação, retornando para Itaituba após a conclusão desta etapa de estudos. Logo ingressou na Rede Estadual por ser a única profissional na área de conhecimento que residia na cidade. Ela narra as dificuldades que enfrentou por morar no oeste do Pará, por causa dos deslocamentos.

Já a história de vida da professora $D$ passa também pela cidade de Belém, onde nasceu e estudou a vida toda. Primeiro fez o curso técnico de ensino médio em eletrônica na Escola Técnica do Estado do Pará (Etepa), tendo já essa familiaridade com a educação profissional e com a docência. Como experiência profissional conseguiu empregos após a formação em nível médio e também após a conclusão da graduação em Ciência da Computação na Universidade da Amazônia (Unama). Após concluir a formação superior trabalhou em empresas, na Secretaria de Educação do Estado do Pará, dando aulas em escolas técnicas estaduais e em serviço técnico no próprio IFPA, como programadora contratada. Depois, foi aprovada em concurso do próprio IFPA para ministrar aulas como professora de disciplinas técnicas.

\section{RESULTADOS E DISCUSSÕES}

Ao serem perguntadas sobre as bases teóricas, percebemos que as professoras entrevistadas não têm a clareza desses conceitos da EPT, o que indica a necessidade de investimento na formação, principalmente voltada aos docentes que ingressaram mais recentemente na instituição. As professoras mais antigas, como as professoras A e C, dizem que aquilo que sabem sobre a EPT aprenderam nos cursos de formação e nas leituras dos documentos. Destacamos que ambas as professoras participaram de espaços de gestão dentro do IFPA.

Em que pese a dificuldade de conceituar as bases da EPT, é possível identificar em suas práticas pedagógicas ou mesmo nas falas, elementos caracterizadores dessas bases, entre elas a busca por uma formação integral, o que pressupõe o rompimento com a educação limitada para a formação profissional, como bem relata a professora C:

O aluno vai ter noções de segurança do trabalho, mas junto com a noção crítica ele vai poder se posicionar. Ele não vai apenas atender a segurança... um exemplo, mas atender a lei que rege a segurança do trabalho, e ele vai se posicionar. Trabalhei com meus alunos sobre a desobediência civil. E o que é a desobediência civil? É quando conflita uma lei legal com uma lei moral. E demonstramos ali em sala de aula (...) que é necessário que você se posicione, não sendo através da violência, mas de uma postura coerente, uma postura crítica, postura em que você impulsiona o teu meio de trabalho [...] Esse aluno não vai sair como um robozinho programado para atender a necessidade do mercado, ele vai sair com uma postura crítica. 
Percebemos o trabalho como princípio educativo na fala da professora B quando descreve sua experiência em trabalhar com projetos com vistas a desenvolver valores nos seus alunos:

A novidade pra mim foi trabalhar com projetos, quando entrei no instituto [...] percebi que além das minhas aulas, dentro de sala de aula, eu poderia trabalhar também num outro horário com os alunos, a fim de mitigar um pouco as dificuldades dele na minha área que é a leitura, a escrita e produção textual e oralidade. Com essa outra professora (se refere à colega de trabalho) nós pudemos fazer isso na pratica, nós escrevemos alguns projetos e no contraturno os alunos se encontravam conosco nos laboratórios ou na sala de aula.

A professora B relata que esse trabalho com projetos acaba por trazer uma melhora significativa nos alunos, não só na parte de aprendizagem, mas de comportamento. Eles acabam prestando mais atenção às aulas, melhoram na produção oral, escrita, seminários e todos os outros tipos de trabalho. A professora entende que é possível trabalhar com projetos porque o IFPA dá condições para isso.

Essa é uma constatação interessante, pois não é possível desenvolver um bom trabalho pedagógico sem que o professor tenha uma boa estrutura, aliás, esse foi o motivo que a professora $B$ alegou para querer trabalhar no IFPA. Vejamos suas considerações sobre sua experiência profissional:

[...] eu queria um datashow, eu pensava em comprar, queria uma caixa de som, eu pensava em comprar, então eu vivia cheia de ideias e não tinha como colocar, pois teria que tirar do meu próprio bolso e não tinha isso no Estado, usava a própria escola do município. Então a partir dali eu via que para fazer do jeito que eu queria eu precisaria mudar. Então vi que o Instituto seria uma possibilidade.

Nas suas falas, a professora $D$ também faz referência à estrutura do IFPA.

[...] A estrutura é muito diferente. Aqui, a gente tem uma estrutura muito interessante, que atende a possibilidade de dar uma boa qualidade do ensino. Lá em Salvaterra é muito precário o ensino (se refere à escola do Estado), a gente praticamente não tinha laboratório. Internet era a coisa mais difícil de ter no campus, e era um campus bem pequeno, que num laboratório de 20 máquinas, no máximo 5 funcionavam. E era nesse nível.

Vimos que a professora B, da educação básica, via no IFPA uma possibilidade de melhorar sua prática, tendo em vista os recursos estruturais oferecidos. Já a professora A, da área técnica, percebia a possibilidade de trabalhar na sua área, como se percebe em seu relato: 
No Estado trabalhei no ensino fundamental. Lá você está para trabalhar somente aquela disciplina, entra no primeiro horário e vai até o final ministrando somente aquela disciplina, não tem nenhum tempo que você possa parar para planejar, para fazer outro tipo de atividade. Quando eu vim para a então Escola Técnica, foi uma realidade bem diferente, porque comecei a aplicar todo meu conhecimento da área de engenharia, consegui me aproximar mais da minha profissionalização. Lá eu trabalhava uma ferramenta da engenharia que era a matemática, aqui consegui aplicar mais os meus conhecimentos.

É pertinente destacar, nas reminiscências das docentes $A$ e $B$, experiências de formação continuada que contribuíram para a melhoria de suas carreiras docentes. Assim, a professora B aponta que a especialização melhorou sua metodologia. Por sua vez, a professora A também destaca a importância da formação continuada, seja para ampliar os horizontes de trabalho, seja para melhorar sua prática:

Em 2005, me afastei para fazer o mestrado que era um grande sonho [...] meu mestrado foi bem direcionado para a área de saneamento. Considero na minha vida profissional que o mestrado foi um divisor de águas. Foi um aprendizado muito grande, né?, enriqueceu muito mesmo.

Para a professora $\mathrm{D}$, a formação continuada possibilitou uma maior compreensão sobre o IFPA, percebendo que ele não é apenas para a formação técnica, mas para direcionar o aluno no prosseguimento dos estudos. Contudo, ela ainda lamenta que em Bragança a maioria dos alunos para no nível médio.

No que diz respeito à identidade dos professores, é interessante a fala da professora $\mathrm{C}$, que afirma ter procurado fugir de perfis estereotipados sobre os profissionais de Filosofia ao descrever:

Porque eu tinha que atender um perfil: primeiro que eles achavam que eu era maconheira, quando descobriram que eu não era maconheira, eu poderia ser sapatão... quando descobriram que eu não era sapatão, eu era aquela marxista revolucionária, quando eles descobriram que eu não era aquela marxista revolucionária, eles ficavam perguntando qual é a tua como professora de Filosofia? Eu disse, gente, eu sou a professora de Filosofia, eu não tenho obrigação de atender as expectativas desses perfis. Sou a profissional.

E esse perfil profissional e a busca por um profissionalismo coaduna com a descrição do tipo de educação que se processou e se busca trabalhar dentro do IFPA, conforme a professora $\mathrm{C}$ aponta nas falas a seguir:

Nós tínhamos uma formação profissional tipo artesão para atender alunos carentes e pobres, aí veio a escola técnica que era só técnico para colocar o aluno ainda no mercado de trabalho, atender ao 
desenvolvimento industrial do país e hoje o que é que nós temos? Nós temos um ensino técnico profissionalizante que não cabe apenas disciplinas técnicas, cabem disciplinas básicas. Isso é uma inovação, mas é um desafio porque você não pode trabalhar mais apenas de formas, a priori como teorias, mas você tem que buscar meios de trabalhar essa prática dentro do teu conteúdo.

A professora C aponta ainda as dificuldades em se ter uma educação integrada na prática docente, nos moldes estabelecidos na legislação e desejada por educadores progressistas:

Foi um desafio dentro do IFPA, porque como aqui tinham as panelinhas, começou-se a abrir um hiato entre os profissionais das disciplinas básicas e os profissionais das disciplinas técnicas, graduados, e com mestrados e doutorados, e disciplinas básicas. Para quê Filosofia num curso técnico? E eu olhava para o professor e dizia: oh, coitado... tu és um robô, criatura? Né? Tu fazes as coisas programadas, apertas botão... porque se o aluno não tiver a formação humana, se ele não tiver essa formação como complemento, dessas exatas, ele será um robô dentro do sistema para atender ao mercado de trabalho.

Essa percepção de separação entre as disciplinas técnicas e básicas são destacadas também nas falas da professora $B$, que apesar de estar a pouco tempo no IFPA, já sente essa separação:

Mas na prática aqui no Instituto é um pouco difícil para entender ainda, se for o ensino médio integrado, a gente compreende que o ensino deveria ser integrado, nós deveríamos formar esses alunos de maneira integral, mas a gente ainda vê uma separação entre as disciplinas gerais e as disciplinas técnicas. Eu sinto falta de uma integração da minha disciplina com o professor da área técnica para gente poder fazer um trabalho junto, visando ali algo com aluno, para que o aluno possa compreender o texto junto com a área de conhecimento. Eu sinto falta disso, dessa integração, dentro do ensino médio integrado que é onde eu mais trabalho.

Não obstante às constatações dessa dicotomia, a experiência cotidiana do fazer docente aponta os caminhos que devemos seguir para a implementação de uma escola politécnica ainda dentro do sistema capitalista, através da paixão pela docência, como se pode perceber na fala da professora C:

[...] E ao me resolver profissionalmente, eu consegui resgatar toda a paixão, todo o amor, todo o... flerte, é como se fosse um novo namorado... Minha profissão é como se fosse um novo... aquele flerte, aquele frisson, quando você vai encontrar um novo namorado, aquele gato... que tu vai toda arrepiada....aquele frio na barriga... quando você vai encontrar alguém que você ama... sabe? (risos). É assim que eu 
estou hoje dentro do IFPA. E houve uma mudança tão profunda em relação ao meu eu, em relação ao meu trabalho, que a professora $\mathrm{C}$ que entrou... a professora $C$ que sofreu esse hiato, essa grande decepção, e a professora $C$ que se resolveu e a professora $C$ que é hoje... é mudança tão radical... tão profunda...

Emerge dessa prática, na voz da professora C, um sentido do trabalho docente que assume a prática de sala de aula e de produção do conhecimento na relação professora e alunos como sendo um misto de doação e profissionalismo.

Podemos perceber o sentido do trabalho também nas falas da professora $A$ :

A relação com os alunos, posso dizer, não sei se é porque amo aquilo que faço, tenho uma grande satisfação em trabalhar, em ter esse contato com os meninos, além de passar conteúdos técnicos, passo ensinamentos de vida. Incrível é que esses alunos que foram nossos alunos lá em 95, 96, 97, às vezes encontramos com eles e eles agradecem o encaminhamento... A gente participou do crescimento da vida profissional deles.

E ela arremata:

Para mim ao trabalhar na educação, o que me dá mais satisfação é ter esse contato com os alunos, é poder ajudar, poder mostrar muitas vezes que um caminho não está certo, que existem outros caminhos. Então, tudo isso. Tenho grande paixão por aquilo que faço, tanto é que pensar em aposentadoria ainda me dói o coração.

A professora $\mathrm{D}$ considera um desafio superar as dificuldades de não ter sido formada em um curso de licenciatura e ainda assim ter que trabalhar com a docência. Por outro lado, mesmo identificando as limitações, reconhece um sentimento de satisfação ao estar na docência ao dizer que: "Mas estar em sala de aula é bem satisfatório, principalmente quando tu tens um aluno que corresponde, né?". E essa mesma professora reconhece um valor muito grande na experiência tanto de ter estudado em uma escola técnica estadual, assim como ter vivenciado empregos na área de conhecimento em que trabalha, apesar de creditar mais preponderância à formação que teve para o mercado.

[...] eu acho que a experiência [...] a nível de empresa foi fundamental [...] até porque a gente tem que passar essa experiência para o aluno de como é trabalhar numa empresa da área que eles estão sendo formados. E eu acho que assim é o ideal. É tu vires do mercado para poder ensinar o que... que você quer que os alunos vão ver lá no mercado...

Como se pode depreender a partir das falas e reminiscências das educadoras entrevistadas, a formação acontece no decurso da vida, vincula-se ao processo de 
escolarização e mesmo antes, porque não se esgota com a conclusão de uma graduação, mas perdura por toda a vida profissional. (GOMES; MARINS, 2004).

\section{CONSIDERAÇÕES FINAIS}

Ao final deste trabalho, renova-se nosso sentimento de fazer parte da construção de uma histórica documental, pois agora os docentes entrevistados saem do anonimato e têm suas vidas relatadas, mesmo que superficialmente. É interessante o agradecimento e a alegria das entrevistadas ao lembrar dos fatos marcantes em suas vidas, das pessoas que lhes ajudaram no percurso histórico, dos desafios familiares e de suas superações.

As considerações em relação às perguntas motivadoras deste trabalho indicam o seguinte: sobre a primeira de como as concepções de EPT são construídas por professoras nos campi de Bragança e Tucuruí, do IFPA, as falas das entrevistadas apontam que o estudo por conta própria, os cursos de formação continuada para a melhoria da carreira docente, o desenvolvimento de projetos que relacionam o ensino com o cotidiano dos alunos e a experiência de gestão e de sala de aula contribuem para a construção das concepções de EPT das professoras dos dois campi. Esse aparato possibilita às professoras uma prática que procura romper com a formação técnica apenas para o que é exigido pelo mercado de trabalho, ao buscar a formação humana e integral para a constituição da cidadania e a superação da dicotomia entre conhecimentos técnicos e gerais por meio da integração de conhecimentos, mesmo enfrentando dificuldades e limitações.

A respeito de quais imagens essas professoras têm de si, a segunda pergunta, as professoras indicam uma autoimagem de identificação profissional com a prática de sala de aula que se constroi ao longo dos anos pela experiência adquirida e pelas condições espaço-temporais disponibilizadas para o exercício da docência. $E$, observando a última pergunta, de como os aspectos de suas histórias de vida repercutem nas suas práticas docentes, as falas das professoras sugerem que a experiência cotidiana delas interliga o profissionalismo e a doação, repercutindo em suas práticas docentes aspectos de suas vidas particulares, já que a trajetória profissional melhora ao longo da vida.

Do ponto de vista científico, e tendo como escopo os objetivos propostos neste trabalho, é importante destacar que se atingiu o resultado, pois percebemos nas histórias de vida, a presença das bases conceituais da EPT, mesmo apresentando alguma limitação em relação à clareza desses conceitos. Percebemos também os processos de identificação de si mesmas ao longo da vida, além do fato de que aspectos de suas vidas repercutem no tipo de profissional que as docentes se tornaram, e que suas relações sociais podem direcioná-las para determinados caminhos, e que só é possível ser um bom profissional se você realmente for apaixonado por sua profissão. 


\section{REFERÊNCIAS}

BRASIL. Lei n. 9.394, de 20 de dezembro de 1996. Estabelece as Diretrizes e Bases da Educação Nacional. Brasília, 1996. Disponível em: http://www.planalto.gov.br/ccivil_03/leis//9394.htm. Acesso em: 25 ago. 2018.

. Lei 11.741, de 16 de julho de 2008. Altera dispositivos da Lei no 9.394, de 20 de dezembro de 1996, que estabelece as diretrizes e bases da educação nacional, para redimensionar, institucionalizar e integrar as ações da educação profissional técnica de nível médio, da educação de jovens e adultos e da educação profissional e tecnológica. Brasília, 2008a. Disponível em: http://www.planalto.gov.br/ccivil_03/_ato2007-2010/2008/lei//11741.htm. Acesso em: 25 ago. 2018.

Lei 11.892, de 29 de dezembro de 2008. Institui a Rede Federal de Educação Profissional, Científica e Tecnológica, cria os Institutos Federais de Educação, Ciência e Tecnologia, e dá outras providências. Brasília, 2008b. Disponível em: http://www.planalto.gov.br/ccivil_03/_ato20072010/2008/lei//11892.htm\#: :text=L11892\&text=LEl\%20N\%C2\%BA\%2011.892\%2C \%20DE\%2029\%20DE\%20DEZEMBRO\%20DE\%202008.\&text=Institui\%20a\%20Red e\%20Federal\%20de,Tecnologia\%2C\%20e\%20d\%C3\%A1\%20outras\%20provid\%C3 \%AAncias. Acesso em: 25 ago. 2018.

CAIRES, Vanessa Guerra; OLIVEIRA, Maria Auxiliadora Monteiro. Educação Profissional Brasileira: da Colônia ao PNE 2014-2024. Petrópolis: Vozes, 2016.

CATTANI, Antonio David; RIBEIRO, Jorge Alberto Rosa. Formação profissional. In: CATTANI, Antonio David; HOLZMANN, Lorena (org.). Dicionário de trabalho e tecnologia. 2. ed. Porto Alegre: Zouk, 2012.

CIAVATTA, Maria. A formação integrada: a escola e o trabalho como lugares de memória e de identidade. In: RAMOS, Marise; FRIGOTTO, Gaudêncio; CIAVATTA, Maria (org.). Ensino Médio Integrado: Concepção e Contradições. São Paulo: Cortez, 2005.

FREITAS, Luiz Carlos de; CALDART, Roseli Salete (org.). A construção da pedagogia socialista. São Paulo: Expressão Popular, 2017.

GOMES, Heloisa Maria; MARINS, Hiloko Ogihara. A ação docente na educação profissional. São Paulo: SENAC, 2004.

NÓVOA, Antonio (org.). Vidas de professores. 2. ed. Porto, Portugal: Porto, 1995.

PISTRAK, Moisey M. Ensaio sobre a escola politécnica. São Paulo: Expressão Popular, 2015.

RAMOS, Marise Nogueira. Concepção do Ensino Médio Integrado à Educação Profissional. In: PARANÀ. Secretaria de Estado da Educação do Paraná (org.). 0 ensino médio integrado à educação profissional: concepções e construções a partir da implantação na rede pública do paraná. Curitiba: SEED-PR, 2009, v. 1. Disponível em: http://forumeja.org.br/go/sites/forumeja.org.br.go/files/concepcao_do_ensino_me dio_integrado5.pdf. Acesso em: 25 ago. 2018. 
Revista Brasileira da Educação Profissional e Tecnológica, v. 1, n. 20, e9951, 2021, p. 16 de 16 CC BY 4.0 | ISSN 2447-1801 | DOI: https://doi.org/10.15628/rbept.2021.9951

SAVIANI, Dermeval. O choque teórico da politecnia. Trabalho, Educação e Saúde, v. 1, 2003. Disponível em: http:http://www.scielo.br/pdf/rbedu/v12n34/a11v1234.pdf. Acesso em: 25 ago. 2018.

SAVIANI, Dermeval. Trabalho e educação: fundamentos ontológicos e históricos. Revista Brasileira de Educação, v. 12, p. 152-165, 2007. Disponível em:http://www.scielo.br/pdf/rbedu/v12n34/a12v1234. Acesso em: 25 ago. 2018. THOMPSON, Paul. A voz do passado: história oral. Rio de Janeiro: Paz e Terra, 2002. 